\title{
Evaluation of Electric-Turbo-Charging applied to Marine Diesel-Engines
}

\author{
Prof R Bucknall, MIET, MSNAME, MIMarEST a,*; Dr S Suárez de la Fuente, AMIMarEST, AMIMechE,

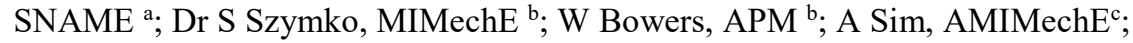 \\ ${ }^{a}$ University College London, London, UK \\ ${ }^{b}$ Bowman Power Group Ltd, Southampton, UK \\ ${ }^{c}$ Rolls Royce PLC, Derby, UK \\ * Corresponding Author. Email: r.bucknall@ucl.ac.uk
}

\begin{abstract}
Synopsis
Electro-Turbo-Compounding (ETC) is a system whereby energy contained in the hot gas of a diesel-engine exhaust is partially recovered through its conversion via a high-speed gas turbine driven alternator into electrical energy. ETC makes a diesel-engine system work more cleanly and effectively thereby improving power density and fuel efficiency. The technology is equally suited to new-build and retrofit applications. Applications to date have been extensive in the $150 \mathrm{~kW}-2 \mathrm{MW}$ range and the $10 \mathrm{MW}-20 \mathrm{MW}$ but almost exclusive to shore-based power stations across the world.
\end{abstract}

This paper reports on the progress of an Innovate UK funded project (2015-18) to develop 'marinised' units with partners UCL, Bowman Power Group Ltd., Lloyd's Register and Rolls Royce PLC. With an expectation on the shipping industry (including naval ships) to reduce their carbon footprint the ETC is suitable for marine engineering application in those ships not easily able to use the conventional Rankine Cycle exhaust gas waste heat recovery system. The paper discussions include the design, modelling and practical testing approaches, results on performance for various arrangements for propulsion and electrical power, and importantly the integration challenge to ensure $\mathrm{NO}_{\mathrm{x}}$ Compliance and Certification.

Within the paper discussion is also made about the financial aspects for propulsion and electric generation applications. The operating profile of different vessels gives different paybacks which are particularly favourable at times of rising fuel prices.

Keywords: Electro-Turbo-Compounding; Payback times; Propulsion; Integration; Marine systems

\section{Introduction}

Marine diesel engines have been widely used by most commercial ships to provide main propulsion and manage service loads. Large two-stroke low-speed diesel engines with a power range of 8-80 MW are typically used as the main propulsion engines utilising waste heat recovery systems to recover energy from the exhaust gases using a Rankine cycle. However, less efficient four-stroke high speed or medium speed marine diesel engines are less commonly equipped with such steam-based waste heat recovery system because they are much smaller in size and, in general, providing less energy efficiency potential from the ship perspective. In smaller vessels a Rankine waste heat recovery system with its boilers, feed water system, condensers etc. would take up substantial space (Suárez de la Fuente, 2016). For these four-stroke engines, the ETC is a potential alternative to recover energy from exhaust gases.

\footnotetext{
* Authors' Biographies

Prof Richard Bucknall is Professor of Marine Systems Engineering at UCL and the Director of Research in the Department of Mechanical Engineering. He began his career with BP Shipping and after a spell with UK MoD working as a Research Fellow at RNEC he joined UCL where he teaches and researchers into propulsion and power.

Dr Santiago Suárez de la Fuente holds a Post-doctoral Research Associate position at UCL's Marine Research Group. Dr Suárez de la Fuente interest are in waste energy recovery, pathways to decarbonise the shipping industry and advanced non-linear optimisation methods for complex engineering systems.

Dr Shinri Szymko is head of Engineering at Bowman Power Group and for the past two decades has been researching and developing high speed turbo-generator systems to improve energy efficiency across a range of applications and sectors.

William Bowers is a Senior Project Manager at Bowman Power Group and holds a BSc (Hons) in Industrial design and Engineering from De Montfort. He has spent over 10 years in Engineering Project Management in the Industrial, Marine and Aerospace sectors.

Alastair Sim is a Technologist in Rolls-Royce's Future Technologies Group. During his time in the research group he has had a particular interest in reciprocating engines which included a secondment into the MTU Friedrichshafen simulation group. He holds a Masters in Aeronautical Engineering from Imperial College London.
} 
The opportunity to augment the benefits of turbocharging four-stroke engines has been investigated, either through the integration of a motor-generator into the turbocharger shaft, or through an additional power turbine, in parallel or in series with the turbocharger. Turbo-compounding can be used to provide additional mechanical power to the engine crankshaft (Zhao et al., 2014), or can provide electrical power to a grid (Kant et al., 2015) and the concept has been used to a range of different applications (Aghaali and Ångström, 2015). The systems have a reasonably small footprint, use non-hazardous materials and have a high level of reliability. Furthermore, Turbomachinery is already widely used within the Royal Navy, and therefore presents a relatively small impact across the Defence Lines of Development, making them a highly suitable Waste Energy Recovery System (WERS) for naval applications.

Therefore, this paper proposes exploring the ETC benefits, payback time and secondary impact when retrofitted to a naval vessel. The paper starts with Section 2, the naval ship and its operational profile, plant layout and sailing time. Section 3 gives a brief discussion about the modelling approach in regards to a four-stroke diesel engine, ETC and the optimisation method used. In Section 4, the results of the simulations are presented and discussed to finally move to the conclusions of this work.

\section{System description}

The ship propulsive plant of the hypothetical frigate is assumed to be a Combined Diesel eLectric Or Gas (CODLOG) formed of four MTU 4000 producing 4,000 kW each with characteristics as shown in Table 1 and a gas turbine.

Table 1: General characteristics of the four-stroke engines installed on-board (Sim, 2017).

\begin{tabular}{cc}
\hline Manufacturer & MTU \\
\hline Model & 4000 \\
\hline Conditions & ISO standard \\
\hline Cylinders & 20 \\
\hline Maximum RPM & $2,000 \mathrm{rpm}$ \\
\hline Maximum power per cylinder & $200 \mathrm{~kW}$ \\
\hline Maximum total power & $4,000 \mathrm{~kW}$ \\
\hline Specific fuel consumption at $85 \% \mathrm{MCR}$ & $217.5 \mathrm{~g} / \mathrm{kWh}$ \\
\hline Bore & $170 \mathrm{~mm}$ \\
\hline Stoke & $190 \mathrm{~mm}$ \\
\hline
\end{tabular}

The hypothetical ship has a constant hotel load of $1,880 \mathrm{~kW}_{\mathrm{e}}$ and has a maximum speed of 30 knots (see Figure 1).

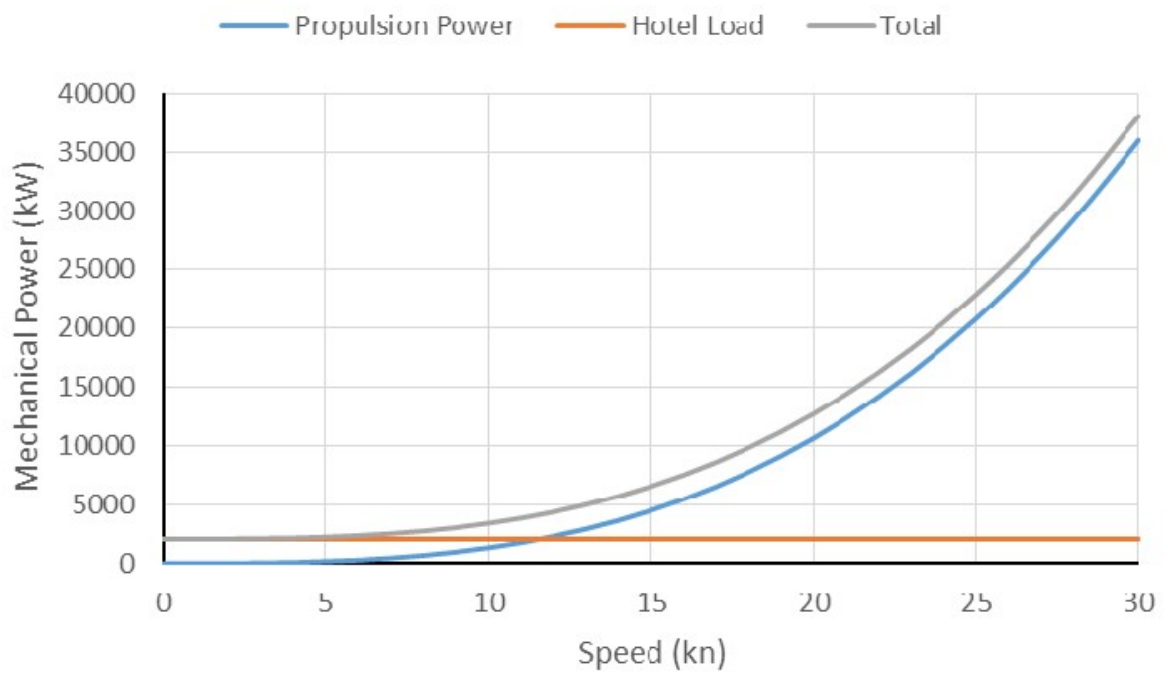

Figure 1: Ship operating profile considering the propulsive power and hotel load. 
The diesel engines are connected to an electrical generator with an assumed constant efficiency of 0.91 (MAN Diesel \& Turbo, 2012a) and produce enough electrical power to cover the propulsive power demand up to 20 knots. Beyond 20 knots the gas turbine covers the propulsive power. At maximum speed the gas turbine generates a power output of $36,000 \mathrm{~kW}$ and delivers it to both shafts via a gearbox, its fuel consumption is as given in Holsonback and Kiehne (2010) and assumes to use further analysis regarding the gas turbine is out of the scope of this work. The ship is assumed to be operating $59 \%$ of the year (i.e. 215 days) with a time distribution as shown in Figure 2.

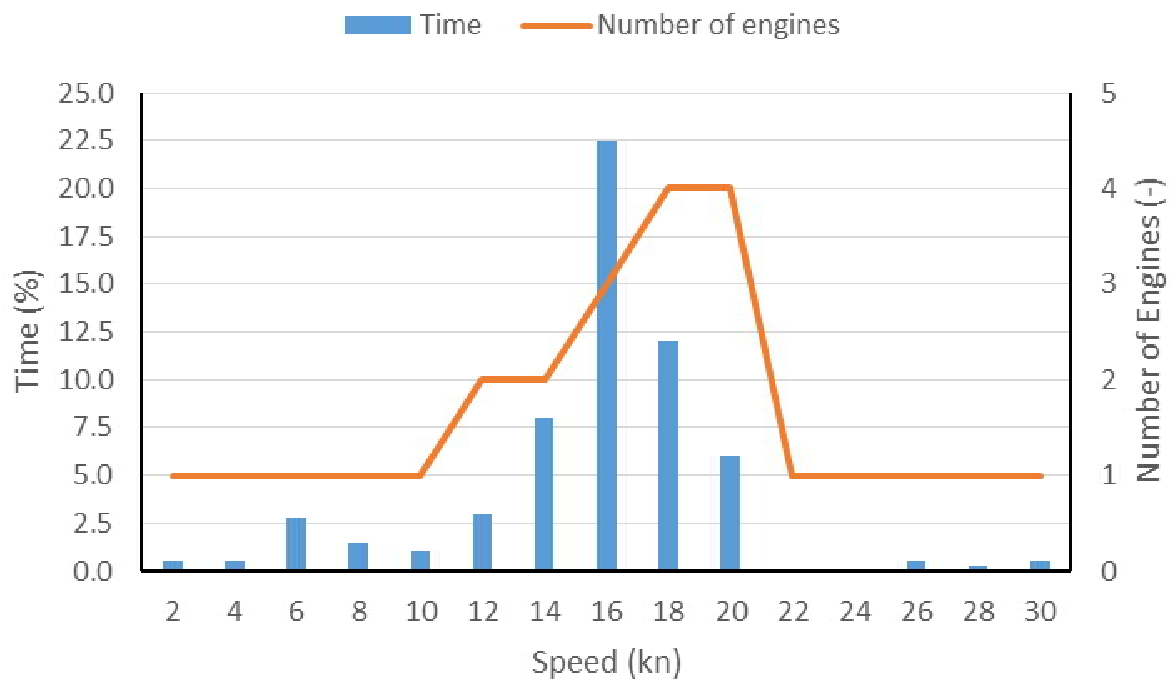

Figure 2: Time distribution and number of diesel engines operating for the hypothetical navy ship. It is assumed that $41 \%$ of the operational time the ship will be offline (Knight, 2016).

\section{Models}

\subsection{Four-stroke diesel engine}

The engine model is based on the five-point Seiliger cycle and uses a zero-dimensional steady-state approach. This offers flexibility to model a wide range of diesel engines under a varied range of operational scenarios. Figure 3 represents the ideal five-point Seiliger cycle consisting of a closed cycle (2-3-4-5-6) and a pumping cycle (7-8$9-2)$. It starts with the compression of pressurised air inside the cylinder (2-3), followed by the heat addition - and combustion - at constant volume represented by $a(3-4)$ and then by heat addition and power output at constant pressure represented by $b$ (4-5). At the end of the expansion stroke (i.e. point 6 ) the exhaust valve opens, and it is assumed, that there is a sudden pressure drop where the closed cycle finishes. At the beginning of the open cycle the piston moves from its Bottom Dead Centre (BDC) to its Top Dead Centre (TDC) pushing out the exhaust gas to the exhaust gas manifold (7-8). At TDS the exhaust gas valve closes and the fresh air intake valve opens (8-9). The piston then moves again to BDC allowing fresh air entering the cylinder and starting the closed cycle again. For the particular equations and modelling approach used for the Seiliger cycle model the following reference is recommended (Ganesan, 2000).

A turbocharger model with an intercooler is connected to the engine model via the intake (Point 2 in Figure 4) and exhaust gas manifold (Point A in Figure 4) models. The TC efficiency is defined by the thermodynamic properties and mass flow rate taken after the TC compressor and turbine. The efficiencies are given in a curve form at a single TC shaft speed extracted from commercially protected TC maps, but it was assumed a maximum efficiency of $82.5 \%$ and $77.0 \%$ for the TC compressor and turbine respectively. The intercooler model has the task of reducing the intake compressed air temperature before arriving to the engine cylinder. This model is simple in its nature since it is not the objective of this work to study the behaviour of a heat exchanger. The intercooler model assumes a constant pressure loss of $10 \mathrm{kPa}$ and uses an effectiveness $(\varepsilon)$ of 0.80 but it adapts to match the minimum and maximum temperatures given by the engine manufacturer.

An engine can have a large set of configuration variables (e.g. how much fuel is used and when it is injected) producing a wide range of specific fuel consumption, exhaust gas characteristics and power outputs. On top of that, information regarding engine and TC tuning under different operating conditions is challenging to obtain, 
making the task of validating the engine model a difficult one. To overcome this challenge, the model is equipped with two different tuning variables - on top of $a$ and $b$ - and an optimisation process that works more like a search tool. The two variables control the heat transfer losses, $B$; and an expansion isentropic efficiency, $\eta_{v}$, which represent the expansion of the exhaust gas into the exhaust gas manifold. The frictional losses are modelled considering engine auxiliary machinery; piston, bearing and rings friction, valve gear losses among others as presented by Ganesan (2000). Additionally, it was assumed that the heat radiation losses $\left(\dot{Q}_{r}\right)$ represent a constant $4 \%$ of the net power output. This assumption is taken from the average losses due to radiation reported in different engine manufacturer data.

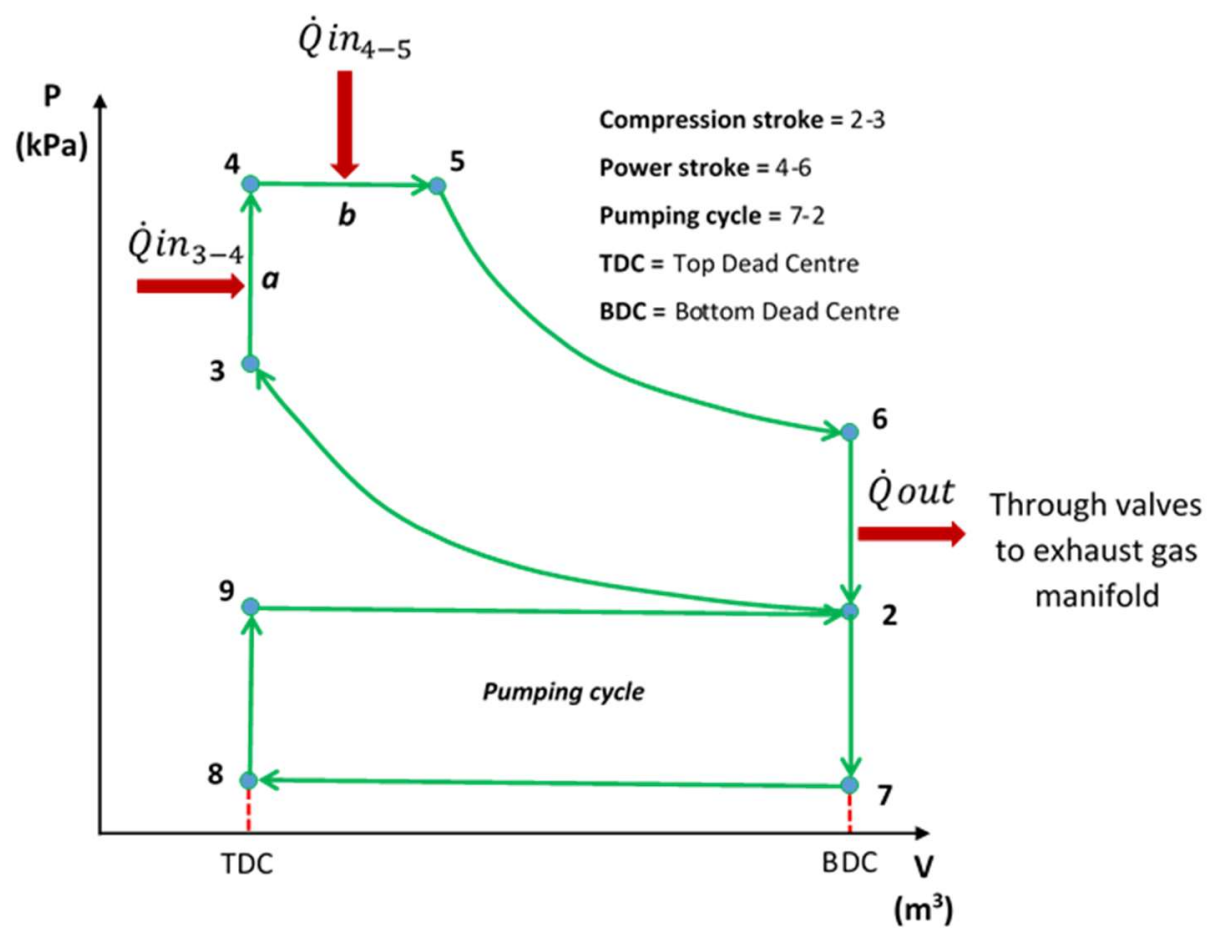

Figure 3: Representation of the five-point Seiliger cycle with the heat addition and heat exhaust indicated used for the modelling of a four-stroke diesel engine.

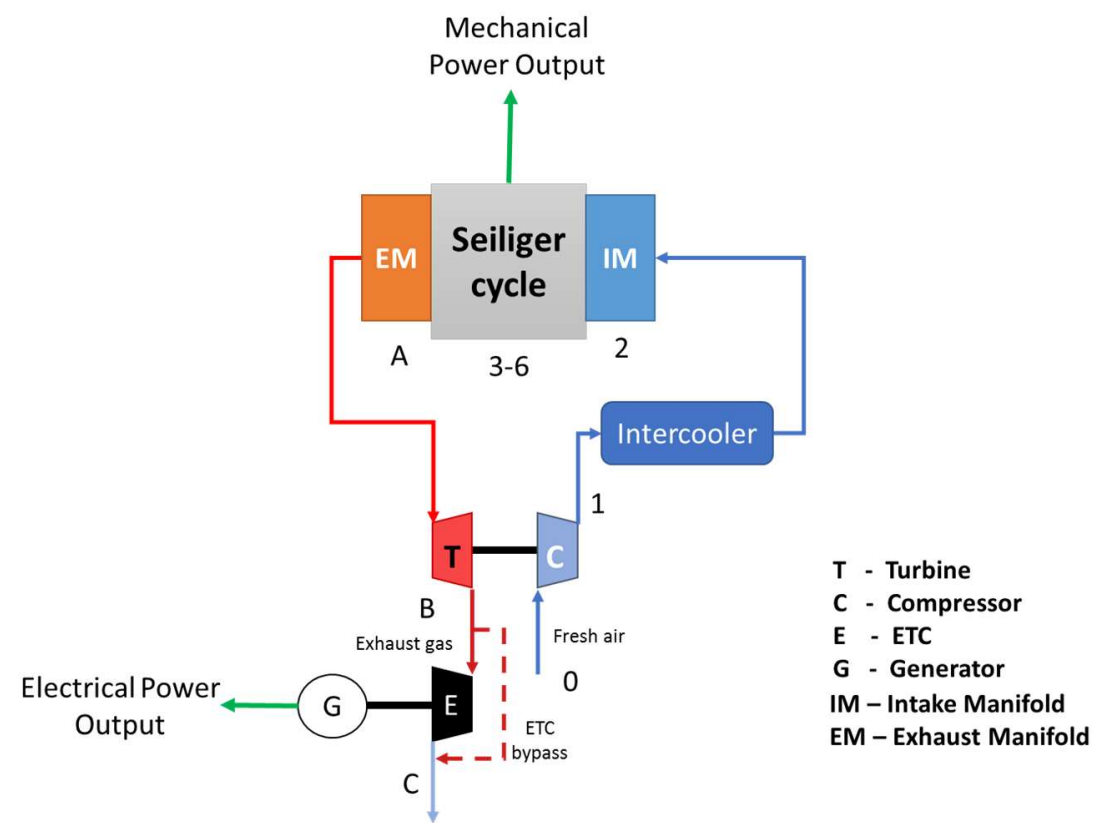

Figure 4: Representation of the Engine Model code with its subcomponents and the ETC module for any engine type. 
The optimisation process uses the single-objective particle swarm method (Kennedy and Eberhart, 1995) and minimises the difference of SFC and mechanical power output between the four-stroke engine (e.g. (MAN Diesel $\&$ Turbo, 2012b)) and the modelled engine. The engine model treats the engine as a single cylinder process to allow for easy scalability for engines families with multiple cylinders.

The net power output $\left(\dot{W}_{t}\right)$, heat input $\left(\dot{Q}_{t}\right)$ and $\operatorname{SFC}\left(S F C_{m}\right)$ are given as follows:

$$
\begin{gathered}
\dot{W}_{t}=\dot{W}_{23}+\dot{W}_{45}+\dot{W}_{56}+\dot{W}_{78}+\dot{W}_{92}+\dot{W}_{f} \\
\dot{Q}_{t}=\dot{Q}_{34}+\dot{Q}_{45}+\dot{Q}_{l}+\dot{Q}_{r} \\
S F C_{m}=\frac{3600 * \dot{Q}_{t}}{L C V * \dot{W}_{t}}
\end{gathered}
$$

Where the power output and inputs through the Seiliger cycle is given by the numerical subscripts and $\dot{W}_{f}$ represents the power loss due to engine friction. The heat transfer losses are represented by $\dot{Q}_{l}$, radiation losses are represented by $\dot{Q}_{r}$ and $L C V$ is the low calorific value which is assumed to be $42,700 \mathrm{~kJ} / \mathrm{kg}$ for Marine Diesel Oil.

To represent the exhaust gas system pressure losses after the TC turbine a constant $4.2 \mathrm{kPa}$ backpressure was assumed.

\section{2. $\quad$ Electric-Turbo-Compounding}

The ETC acts as an obstruction in the exhaust gas flow, the exhaust gas starts to accumulate raising the pressure at the ETC entrance - and TC turbine exit - to then convert this energy to kinetic energy inside the ETC turbine. The ETC design expansion ratio (ER) is selected by the optimisation process which allows to determine the TC backpressure $\left(P_{B}\right)$ by multiplying $P_{9}$ by the ER. The torque and speed in the ETC turbine shaft is converted to electrical power $\left(\dot{W}_{e, E T C}\right)$ via an electrical generator and power electronics, it is reasonable to assume a constant electrical efficiency $\left(\eta_{e, E T C}\right)$ of a value of $93.5 \%$. The electrical power generated by the ETC $\left(\dot{W}_{e, E T C}\right)$ can be found as follows:

$$
\dot{W}_{e, E T C}=\dot{m}_{e x} * \eta_{e, E T C} * B P *\left(h_{C}-h_{B}\right)
$$

Where $h_{B}$ and $h_{C}$ are the specific enthalpy of the exhaust gas before and after its expansion in the ETC respectively. The $B P$ variable represents the proportion of exhaust mass deviated from the ETC entrance to regulate the power production if it is needed. The ETC isentropic efficiency $\left(\eta_{E T C}\right)$ at design point can be as high as $86.0 \%$ but for this analysis is assumed at $82.5 \%$ and it was used to determine $h_{C}$ :

$$
h_{C}=h_{B}+\eta_{E T C} *\left(h_{C S}-h_{B}\right)
$$

Where $h_{C s}$ is the specific enthalpy assuming that the expansion through the ETC is isentropic.

Each ETC is assumed to have a maximum electrical power generation of $110 \mathrm{~kW}_{\mathrm{e}}$ with initial specific cost of $£ 700 / \mathrm{kW}_{\mathrm{e}}$ and $£ 0.3 / \mathrm{h}$ for the operational cost.

\subsection{Fuel consumption and Energy Efficiency Design Index}

For the case when the ETC is being retrofitted to the main engine, the fuel consumption for the different machinery is calculated as follows: only the benefit and secondary effects are considered from the auxiliary engine side. The total fuel consumption $\left(F C_{t}\right)$ in tonnes for a ship without ETC are given by:

$$
\begin{gathered}
F C_{M E, E T C}=\frac{\sum_{i=0}^{O S} \sum_{j=0}^{O M} N_{M E}(i, j) * \dot{W}_{M E, E T C}(i, j) * S F C_{m, E T C}(i, j) * t_{E T C}(i, j)}{10^{6}} \\
\dot{W}_{M E, E T C}=c y l * \dot{W}_{t, E T C} \\
F C_{A E, E T C}=\frac{\sum_{i=0}^{O S} \sum_{j=0}^{O M} N_{A E}(i, j) * \dot{W}_{A E}(i, j) * S F C_{A E}(i, j) * t_{E T C}(i, j)}{10^{6}} \\
F C_{t, E T C}=F C_{M E, E T C}+F C_{A E, E T C}
\end{gathered}
$$


Where $N$ refers to the number of operational engines, $O S$ refer to the operational speeds, $O M$ is the months, $\dot{W}_{M E, E T C}$ is the four-stroke diesel engine net power output when the ETC has been retrofitted, $S F C_{m, E T C}$ is the main engine's specific fuel consumption with ETC for the power demanded and $t_{E T C}$ is the time spent at each operational speed and condition, $c y l$ refers to the number of cylinders for the modelled main engine. The total fuel consumed is represented by $F C_{t, E T C}$ while $F C_{M E, E T C}$ and $F C_{A E, E T C}$ represents the fuel consumed by the main and auxiliary machinery after the ETC has been retrofitted. The total fuel savings $\left(F S_{E T C}\right)$ can be calculated by subtracting $F C_{t, E T C}$ from the total fuel consumed by the same vessel without ETC. For the $\mathrm{CO}_{2}$ emission calculation a carbon factor for MDO of $3.206 \mathrm{t} \mathrm{CO}_{2} / \mathrm{t}$ of fuel is used (International Maritime Organization, 2014) while for the fuel cost it was assumed a value of $£ 392.9 / t$ - average cost of MDO between April 2017 and April 2018 (Bunker Index, 2018).

\subsection{Approach}

For this work a sensitivity analysis will be done to the hypothetical frigate which is being retrofitted with an ETC for the four engine generators. The ETC ER to be explored go from 1.1 to 1.7 in steps of 0.2 and the design points for the ETC are $75 \%$ MCR and $85 \%$ MCR. The impact of the ETC electrical power output on the ship's fuel consumption, backpressure increment, $\mathrm{CO}_{2}$ emission, operational costs and payback times will be explored. The electrical loads demanded by the ship are going to be used to represent the different operational points with and without the ETC since the electrical demand is assumed to be constant.

\subsection{Software used}

The engine and ETC thermodynamics, vessel's operating profile and annual performance are modelled using Matlab. Additionally, CoolProp (Bell et al., 2014) was used for the calculation of the thermodynamic properties of air, combustion components and exhaust gas.

\section{Results}

Looking into a single four-stroke engine, it can be said in general, that as the ETC design ER increases the larger it is capable of producing electricity (see Figure 5). Larger design ER produce a larger obstruction for the exhaust gas flow which in turn allow for a larger energy harvesting. The ETC produces more electricity at the higher engine loadings due to more exhaust gas flowing and larger operational ERs. The maximum electrical power generated by an ETC on board the frigate is $680 \mathrm{~kW}_{\mathrm{e}}$ for an ETC with an ER of 1.7 at the $75 \%$ electrical maximum continuous rating (MCRe). An ETC with an ER of 1.1 does not produce any electrical power below the

$70 \%$ MCRe when the design point is set at $85 \%$ MCRe while for a design point of $75 \%$ MCRe there is no ETC power production below $60 \%$ MCRe. An interesting point to highlight is the fact that any ETC designed for an electrical load of $75 \%$ MCRe (Figure 5A) produces more electrical power than an ETC designed at $85 \% \mathrm{MCRe}$ (Figure 5B). At low loads the 75\% MCRe ETC has better turbine and ETC efficiencies than the $85 \%$ MCRe while at high loads the operational ER are larger for the $75 \%$ MCRe design. As an example, using a design ER of 1.7 and looking at the $95 \% \mathrm{MCRe}$, the operational ER for the $75 \% \mathrm{MCRe}$ is about 2.0 with an inlet pressure of $204 \mathrm{kPa}$ while the $85 \%$ MCRe has an operational ER of 1.8 with an inlet pressure of $187 \mathrm{kPa}$. This large pressure difference overcomes the lower efficiencies on the $75 \%$ MCRe at high loads in regards to electrical power production. However, this causes as well a larger engine backpressure which will impact the pumping cycle, thermal efficiency and SFC of the four-stroke diesel engine.

Looking into a single cylinder Figure 6A and 6B present the change in mechanical power output due to the retrofit of an ETC at different design points. The change in cylinder power is caused mainly by a lower demand of electrical power for the engines due to the participation of the ETC in the generation process and an increase in cylinder backpressure which increases the engine pumping losses and hence the engine thermal efficiency. As the ER increases, and fixing the electrical load, the reduction in cylinder power output reduces having a maximum reduction of nearly $20 \%$ at $95 \%$ MCRe with a design point of $75 \%$ MCRe. 

A)
DP 75\% MCRe

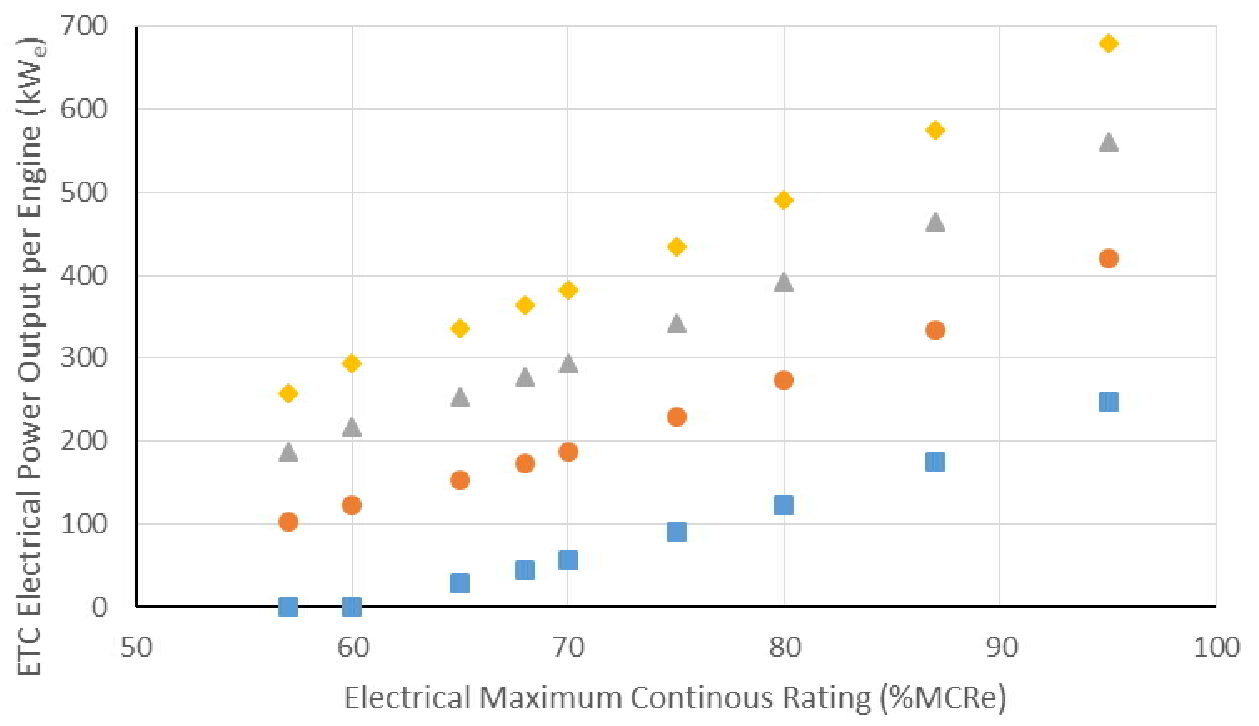

—ER 1.1

- ER 1.3

A ER 1.5

- ER 1.7

B)

DP $85 \%$ MCRe

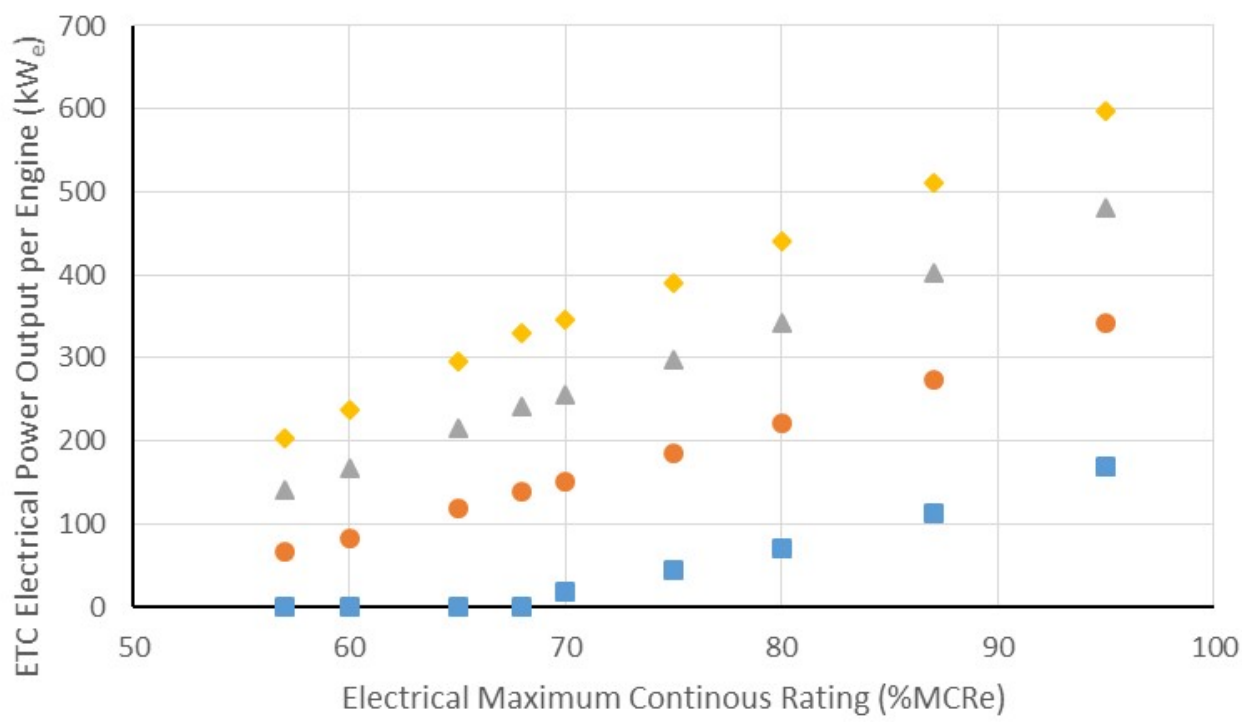

Figure 5: Electrical power generated per engine by the ETC being retrofitted for two different design points: A) 75\% MCRe, B) 85\% MCRe.

The maximum backpressure increases of $227 \mathrm{kPa}$ is seen for an ETC with a design ER of 1.7 and designed for the $75 \%$ MCRe point, this represents an increment of 68\% (see Figure 7A). For the same design ER but a design point of $85 \%$ MCRe the increment reaches $165 \mathrm{kPa}$, a change of $49 \%$ (see Figure $7 \mathrm{~B}$ ). This is a relevant consideration since it will not only degrade the engines SFC but also with a larger pressure at the exhaust gas manifold, and depending on the valve timing, a larger exhaust gas mass gets trapped in the cylinder and raising the new charge air temperature which will have knock off effect on the combustion temperature (Ganesan, 2000). Higher combustion temperatures inside the diesel engine cylinder promote the formation of $\mathrm{NO}_{\mathrm{x}}$ which could require an engine $\mathrm{NO}_{\mathrm{x}}$ recertification (Lloyd's Register, 2018). It is also relevant to highlight that with a certain degree, and depending on the valve timing of the engine, the backpressure can generate an internal exhaust gas recirculation which helps to reduce the formation of $\mathrm{NO}_{\mathrm{x}}(\mathrm{Mittal}$, Donahue and Winnie, 2015). The TC remap for its use with the ETC causes for ETC with design ER of 1.1 a lower backpressure as the engine without the ETC. 

A)
DP $75 \%$ MCRe

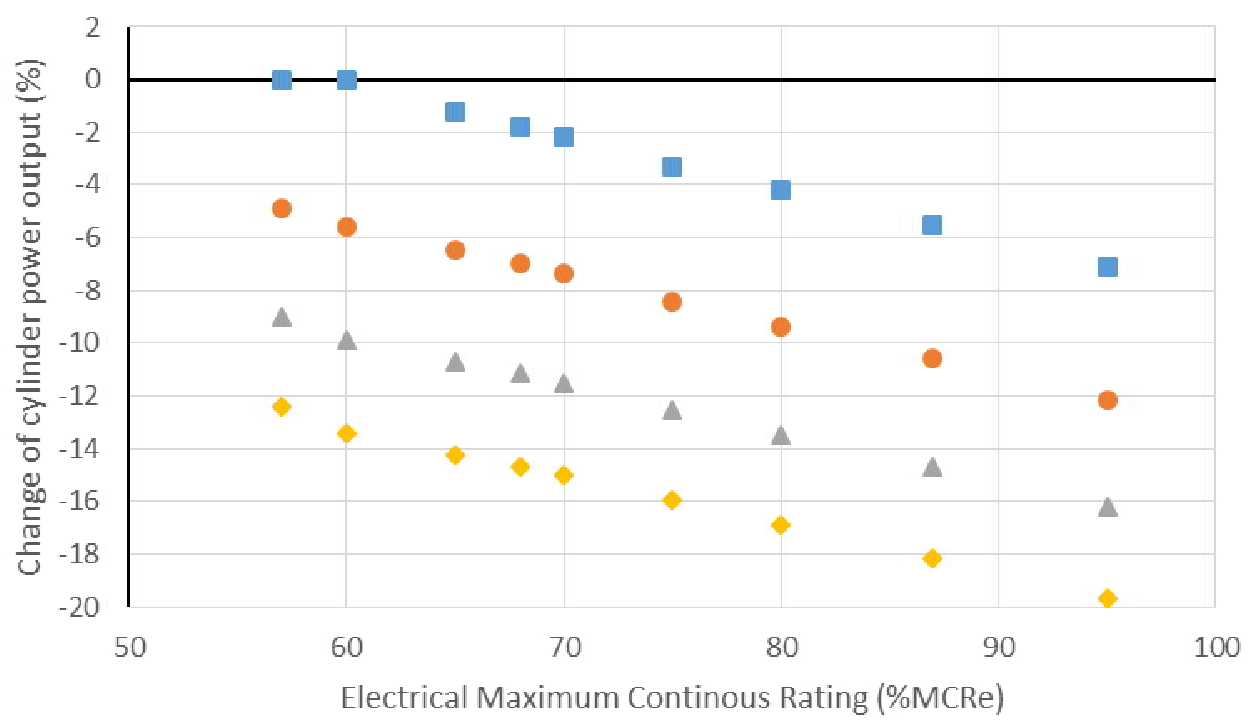

ER 1.1

- ER 1.3

$\Delta$ ER 1.5

- ER 1.7

B)

DP $85 \%$ MCRe

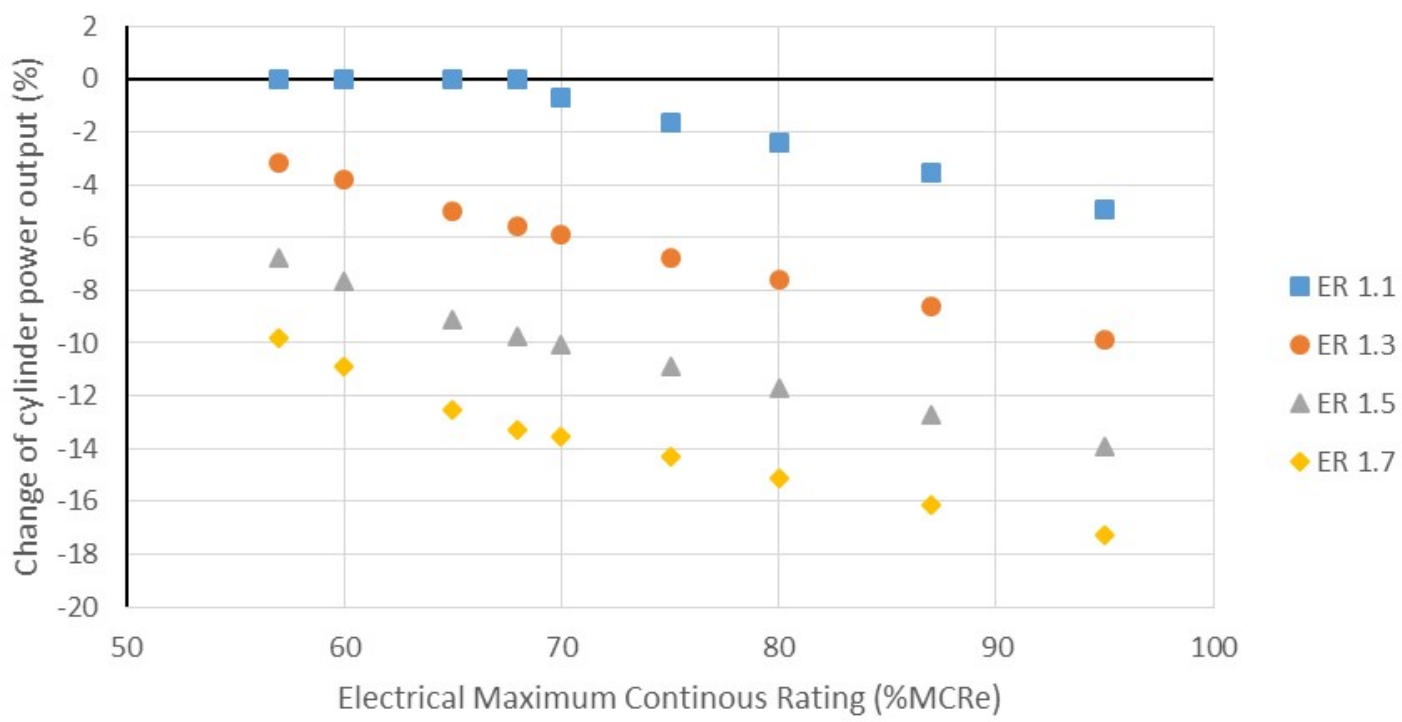

Figure 6: Mechanical power change due to the ETC being retrofitted for two different design points:

A) $75 \%$ MCRe, B) $85 \%$ MCRe.

The frigate annual fuel consumption without an ETC installed is of $680 \mathrm{t}$ per year of which $633 \mathrm{t}$ are consumed by the four-stroke diesel engines and $47 \mathrm{t}$ by the gas turbine. The total annual $\mathrm{CO}_{2}$ emissions by the hypothetical frigate is then 2,180 t. Table 2 shows that a maximum fuel savings of $8.8 \%$, accounting for the gas turbine annual fuel consumption, is achieved by a design ER of 1.7 designed for the 75\% MCRe which represents about $60 \mathrm{t}$ of fuel per year or $£ 23,500$. The larger savings of an ETC designed for the $75 \%$ MCRe is due to larger operational ER.

A higher design ER has a higher initial cost due to the maximum electrical power output as seen in Figure 5 and this will cause a larger initial cost. The maximum initial total cost is seen for a design ER of 1.7 at $75 \% \mathrm{MCRe}$ at $£ 1.55$ million which reflect the fact that it will need seven $110 \mathrm{~kW}_{\mathrm{e}}$ ETC per engine. At the lower end of the ER spectrum, the initial cost of a design ER at $85 \%$ MCRe has an initial cost of $£ 390,000$ with just two ETC per engine. The fact that each engine has to be fitted with the same number of ETC and that the frigate will be operating 
for only $59 \%$ of the year - of which $31 \%$ of the time will see the four diesel engines working - produces payback times as low as 8.4 years (see Figure 8). It is seen that there are similar payback times for the larger design ER for both design loading conditions, this is due to in one hand the lower initial costs of lower design ER but as well for $85 \%$ MCRe ETC and in the other the higher electrical generation of the $75 \%$ MCRe manages to save enough fuel to overcome the initial investment difference.

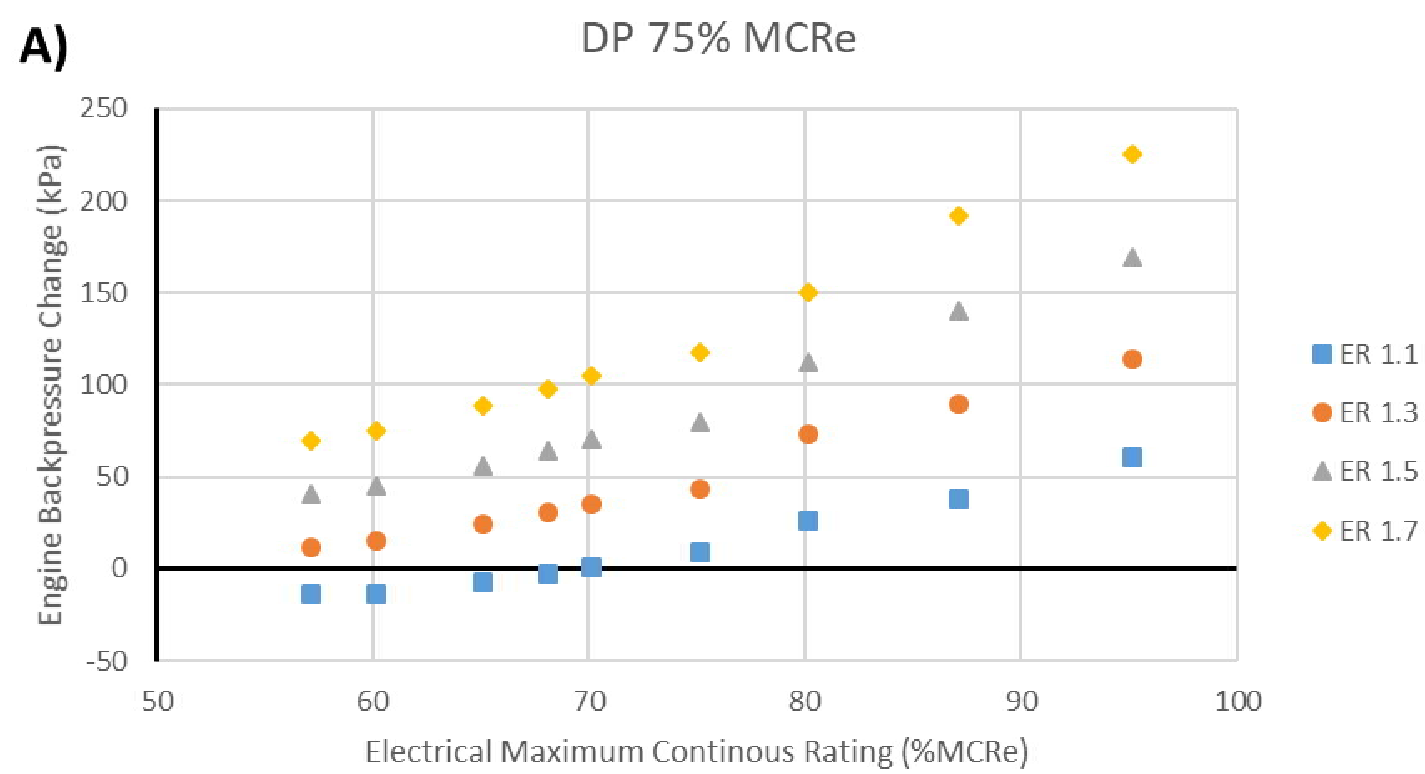

B) $\quad$ DP $85 \% \mathrm{MCRe}$

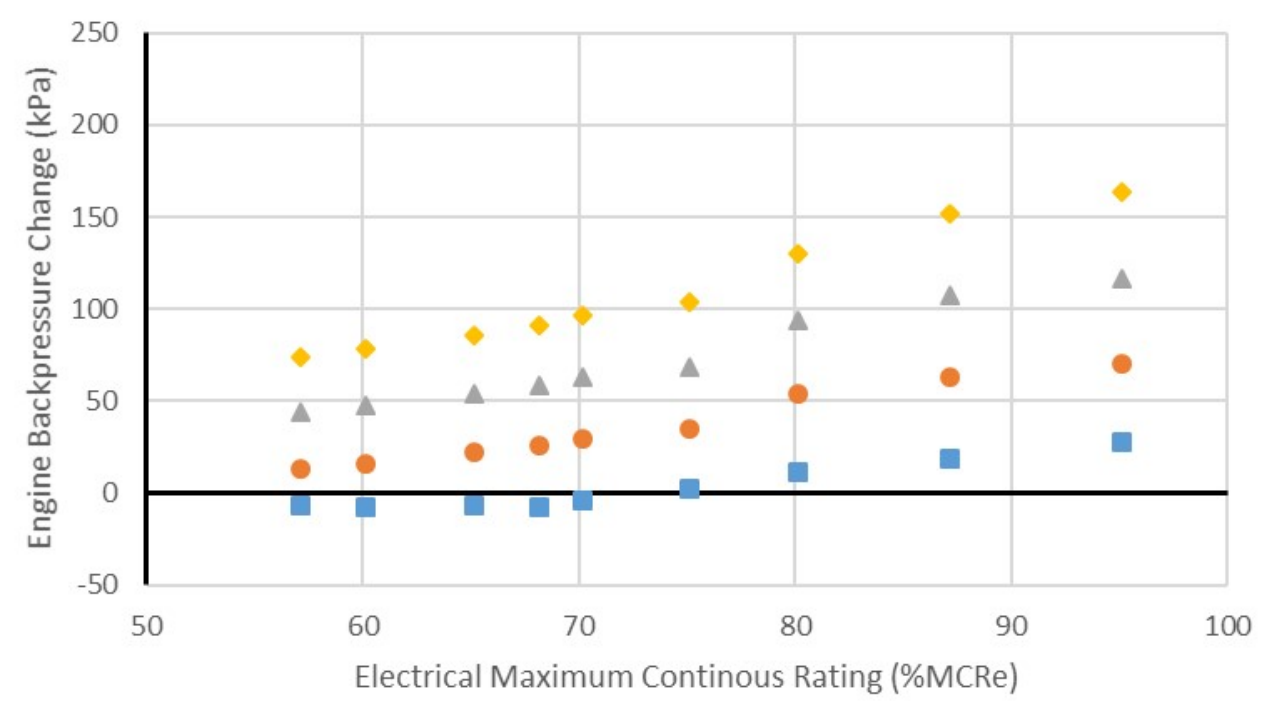

ER 1.1

- ER 1.3

$\Delta$ ER 1.5

• ER 1.7

Figure 7: Change in engine backpressure due to the ETC being retrofitted for two different design points: A) $75 \%$ MCRe, B) $85 \%$ MCRe.

Table 2: Fuel savings achieved by retrofitting an ETC to the frigate four-stroke diesel engines.

ETC Design Expansion Ratio (-)

\begin{tabular}{ccccc}
\hline Engine Design Point (\% MCRe) & $\mathbf{1 . 1}$ & $\mathbf{1 . 3}$ & $\mathbf{1 . 5}$ & $\mathbf{1 . 7}$ \\
\hline $\mathbf{7 5}$ & $2.1 \%$ & $5.2 \%$ & $7.3 \%$ & $8.8 \%$ \\
$\mathbf{8 5}$ & $1.0 \%$ & $4.2 \%$ & $6.4 \%$ & $7.9 \%$ \\
\hline
\end{tabular}




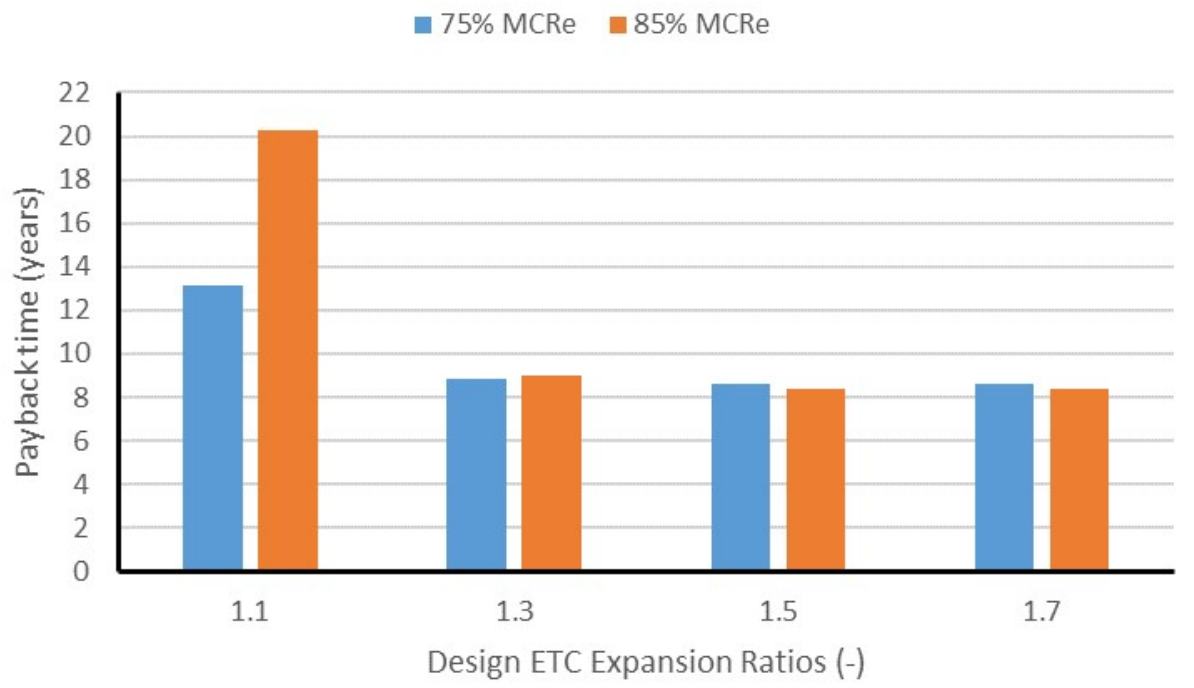

Figure 8: Payback time for the different ETC designs retrofitted to the frigate.

Under this evidence an optimal and suitable ETC design for the frigate will lay between the design ER 1.3 and 1.5 at $85 \%$ MCRe since it will offer a comparatively good payback time (i.e. between 8.4 and 9.0 years), a lower system complexity per engine (i.e. between two and four ETC per engine) and a reasonable maximum engine backpressure (i.e. between 70 and $120 \mathrm{kPa}$ ) that may not cause an engine recertification.

\section{Conclusions and further research}

The ETC expansion ratio explored went from 1.1 to 1.7 with design points of $75 \%$ MCRe and $85 \%$ MCRe. It was seen that the an ETC with the highest ER at design point can produce up to $680 \mathrm{kWe}$ per engine which delivers an annual fuel savings of $60 \mathrm{t}$ of fuel, represents a $\mathrm{CO}_{2}$ emission reduction of $8.8 \%$ and $£ 23,500$ less in operational costs. Depending on the ETC design ER and engine loading condition the initial cost fluctuates between $£ 120,000$ and $£ 450,000$ with the higher initial costs found for the larger ER due to the higher power generated. The payback times for the different ETC designs were found between 8.4 and 20.1 years, having the shortest payback time an ETC system with a design ERs of 1.5 and 1.7 designed at $85 \%$ MCRe. In regards to the backpressure, it can be seen that the ETC with a design ER of 1.7 and a design point of $75 \%$ MCRe had the largest backpressure increment at $227 \mathrm{kPa}$ or $68 \%$ of the original engine backpressure, this was caused by larger operational ERs when compared to ETC designed at the $85 \%$ MCRe. Larger engine backpressures can be associated with the formation of $\mathrm{NO}_{\mathrm{x}}$ due to higher temperatures in the combustion chamber, this in turn could trigger the retrofitted engine with a $\mathrm{NO}_{\mathrm{x}}$ recertification. However, it was discussed that by having part of the exhaust gas inside the cylinder causes a reduction of oxygen available for combustion and $\mathrm{NO}_{\mathrm{x}}$ formation, acting like a natural exhaust gas recirculation process. In general, it can be said that that an ETC designed with an ER between 1.3 and 1.5 at $85 \%$ MCRe can bring good fuel savings, comparability good payback time and reasonable maximum backpressure increment due to the installation of the ETC. Future work will focus into this critical part as well as the valve overlap configuration for different four-stroke engines.

\section{References}

Aghaali, H. and Ångström, H.-E. (2015) 'A review of turbocompounding as a waste heat recovery system for internal combustion engines', Renewable and Sustainable Energy Reviews, 49, pp. 813-824. doi: 10.1016/j.rser.2015.04.144.

Bell, I. H. et al. (2014) 'Pure and Pseudo-pure Fluid Thermophysical Property Evaluation and the Open-Source Thermophysical Property Library CoolProp.', Industrial \& engineering chemistry research. American Chemical Society, 53(6), pp. 2498-2508. doi: 10.1021/ie4033999.

Bunker Index (2018) Bunker Index, Prices. Available at: http://www.bunkerindex.com/prices/bixfree.php?priceindex_id=4\#Description (Accessed: 5 December 2014). 
Ganesan, V. (2000) Computer Simulation of Compression-Ignition Engine Processes. 1st edn. Himayatnagar: University Press (India).

Holsonback, C. R. and Kiehne, T. M. (2010) 'Thermal aspects of a shipboard integrated electric power system', in 2010 IEEE International Conference on Automation Science and Engineering. Toronto: IEEE, p. 8. doi: 10.1109/COASE.2010.5584728.

International Maritime Organization (2014) Third IMO Greenhous Gas study 2014. London, UK: IMO.

Kant, M. et al. (2015) 'Heavy-duty engine electric turbocompounding', Proceedings of the Institution of Mechanical Engineers, Part D: Journal of Automobile Engineering. SAGE PublicationsSage UK: London, England, 229(4), pp. 457-472. doi: 10.1177/0954407014547237.

Kennedy, J. and Eberhart, R. (1995) 'Particle swarm optimization', in Proceedings of ICNN'95 - International Conference on Neural Networks. Perth: IEEE, pp. 1942-1948. doi: 10.1109/ICNN.1995.488968.

Knight, D. (2016) Waste Heat Recovery in Warships Using Turbo-Generator Units. UCL.

Lloyd's Register (2018) 'System Requirements: LR Review of Class and Statutory Requirements Impacting the Application of ETC Technology'. Southampton: Lloyd's Register, p. 30.

MAN Diesel \& Turbo (2012a) Diesel-electric Drives.

MAN Diesel \& Turbo (2012b) 'L21/31 Project Guide - Marine’. Augsburg: MAN Diesel \& Turbo, p. 354. Available at:

https://marine.mandieselturbo.com/applications/projectguides/4stroke/manualcontent/Mobile/PG_MII_L2131.pdf.

Mittal, M., Donahue, R. and Winnie, P. (2015) 'Evaluating the Influence of Exhaust Back Pressure on Performance and Exhaust Emissions Characteristics of a Multicylinder, Turbocharged, and Aftercooled Diesel Engine', Journal of Energy Resources Technology. American Society of Mechanical Engineers, 137(3), p. 032207. doi: 10.1115/1.4029383.

Sim, A. (2017) 'Private Communications about MTU’s 4000 engine’. Derby: Rolls-Royce PLC, p. 1.

Suárez de la Fuente, S. (2016) Reducing Shipping Carbon Emissions under Real Operative Conditions: A Study of Alternative Marine Waste Heat Recovery Systems based on the Organic Rankine Cycle. UCL.

Zhao, R. et al. (2014) 'Parametric study of power turbine for diesel engine waste heat recovery', Applied Thermal Engineering. Pergamon, 67(1-2), pp. 308-319. doi: 10.1016/J.APPLTHERMALENG.2014.03.032. 


\section{Nomenclature}

\begin{tabular}{|c|c|c|c|c|c|}
\hline Symbol & Name & Units & Symbol & Name & Units \\
\hline$B P$ & $\begin{array}{c}\text { Exhaust gas bypass } \\
\text { proportion }\end{array}$ & - & $O M$ & Number of operating months & - \\
\hline$c y l$ & Cylinder number & - & $O S$ & Number of operating speeds & - \\
\hline$F C$ & Fuel consumption & $\mathrm{t}$ & $P$ & Pressure & $\mathrm{kPa}$ \\
\hline$h$ & Specific enthalpy & $\mathrm{kJ} / \mathrm{kg}$ & $\dot{Q}$ & Heat & $\mathrm{kW}$ \\
\hline$L C V$ & Low Calorific Value & $\mathrm{kJ} / \mathrm{kg}$ & $S F C$ & Specific fuel consumption & $\mathrm{g} / \mathrm{kWh}$ \\
\hline$\dot{m}$ & Mass flow rate & $\mathrm{kg} / \mathrm{s}$ & $t$ & Time & $\mathrm{h}$ \\
\hline$N$ & Number of engines & - & $\dot{W}$ & Power & $\mathrm{kW}$ \\
\hline $\begin{array}{c}\text { Greek } \\
\text { Symbol }\end{array}$ & Name & Units & & & \\
\hline$\eta$ & Efficiency & $\%$ & & & \\
\hline $\begin{array}{l}\text { Subscripts and } \\
\text { superscripts }\end{array}$ & \multicolumn{2}{|c|}{ Name } & $\begin{array}{l}\text { Subscripts and } \\
\text { superscripts }\end{array}$ & \multicolumn{2}{|l|}{ Name } \\
\hline$A E$ & \multicolumn{2}{|c|}{ Auxiliary engine } & $l$ & \multicolumn{2}{|c|}{ Heat transfer losses } \\
\hline$B$ & \multicolumn{2}{|c|}{ Backpressure } & $m$ & \multicolumn{2}{|c|}{ Mechanical } \\
\hline$E R$ & \multicolumn{2}{|c|}{ Expansion Ratio } & $M E$ & \multicolumn{2}{|c|}{ Main Engine } \\
\hline ETC & \multicolumn{2}{|c|}{ Electro-Turbo-Compounding } & $r$ & \multicolumn{2}{|c|}{ Radiation losses } \\
\hline$e$ & \multicolumn{2}{|c|}{ Electric/Electrical } & $s$ & \multicolumn{2}{|l|}{ Isentropic } \\
\hline$f$ & \multicolumn{2}{|c|}{ Frictional } & $t$ & \multicolumn{2}{|l|}{ Total/Net } \\
\hline
\end{tabular}

